\title{
Quasi-periodic oscillations of aerosol backscatter profiles and surface meteorological parameters during winter nights over a tropical station
}

\author{
M. G. Manoj and P. C. S. Devara \\ Indian Institute of Tropical Meteorology, Pashan, Pune, India \\ Received: 17 July 2010 - Revised: 17 February 2011 - Accepted: 25 February 2011 - Published: 4 March 2011
}

\begin{abstract}
Atmospheric gravity waves, which are a manifestation of the fluctuations in buoyancy of the air parcels, are well known for their direct influence on concentration of atmospheric trace gases and aerosols, and also on oscillations of meteorological variables such as temperature, wind speed, visibility and so on. The present paper reports quasiperiodic oscillations in the lidar backscatter signal strength due to aerosol fluctuations in the nocturnal boundary layer, studied with a high space-time resolution polarimetric micro pulse lidar and concurrent meteorological parameters over a tropical station in India. The results of the spectral analysis of the data, archived on some typical clear-sky conditions during winter months of 2008 and 2009, exhibit a prominent periodicity of 20-40 $\mathrm{min}$ in lidar-observed aerosol variability and show close association with those observed in the near-surface temperature and wind at 5\% statistical significance. Moreover, the lidar aerosol backscatter signal strength variations at different altitudes, which have been generated from the height-time series of the one-minute interval profiles at $2.4 \mathrm{~m}$ vertical resolution, indicate vertical propagation of these waves, exchanging energy between lower and higher height levels. Such oscillations are favoured by the stable atmospheric background condition and peculiar topography of the experimental site. Accurate representation of these buoyancy waves is essential in predicting the sporadic fluctuations of weather in the tropics.
\end{abstract}

Keywords. Atmospheric composition and structure (Aerosols and particles)

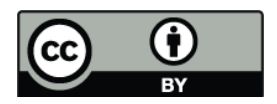

Correspondence to: P. C. S. Devara (devara@tropmet.res.in)

\section{Introduction}

Atmospheric gravity waves are essential parts of the dynamics of the atmosphere on all meteorological scales (Nappo, 2002), and their presence in a stably stratified environment could be an important feature of many mountainous/hilly regions (e.g., Ross and Vosper, 2003). They are manifested as oscillations of air parcels by the lifting force of buoyancy and the restoring force of gravity; and disturbances to this type of balanced state result in the excitation of atmospheric gravity waves with a variety of spatial and temporal scales (Fritts and Alexander, 2003; Geller et al., 2006). Since these waves occur at all altitudes in the atmosphere, they are important for several reasons: they can transport energy and momentum from one region of the atmosphere to another; they can initiate and modulate convection and subsequent hydrological processes (e.g., Mapes, 1993); they disturb the smooth, balanced state through wave breaking and associated generation of turbulence and help in the mixing of chemical species.

It is worthwhile to note that small-scale gravity waves are a key element in defining the large-scale circulation, the thermal and chemical constituent distributions, and the variability of the atmosphere from the troposphere to the lower thermosphere (Geller et al., 2006). These Internal Gravity Waves (IGWs) can have any frequency between zero and a maximum value which is equal to the local Brunt-Vaisala frequency $-N_{\mathrm{B}}$ (Gill, 1982). Earlier studies (e.g. Duynkerke, 1991) have shown that gravity waves cause quasi-periodic oscillation of meteorological variables such as temperature, wind speed, visibility and so on. Roach (1976) reported oscillations in wind speed with a period of $10-15$ min which are associated with gravity waves. Devara et al. (1994) had undertaken a study regarding the associationship of meteorological parameters on aerosol concentrations on longterm basis and reported significant near-common periodicities in both of them. It is believed that gravity waves due

Published by Copernicus Publications on behalf of the European Geosciences Union. 
to atmospheric instabilities have a direct bearing on the drop size distribution of drizzle, fog (Nilsson, 1996; Nilsson and Bigg, 1996), liquid water content and downward radiative flux (Welch et al., 1986).

The influence of gravity waves on atmospheric constituents such as aerosols is also a key point of attention as the variability in the latter component is directly responsible for the radiative effects and indirectly accountable for cloud microphysical processes (Jayaraman et al., 1998; IPCC, 2001; Menon et al., 2002; Vinoj et al., 2004; Tripathi et al., 2005; Niranjan et al., 2007; Pandithurai et al., 2008). Tropospheric aerosols are quite variable in their production and residence time. To account for their effects on weather and climate, it is essential that their unevenness be predictable to the extent possible. Though the temporal variability of aerosols is highly non-linear, their predictable characteristics can be achieved provided it is associated with well known causative as well as periodic processes. The stably stratified atmospheric boundary layer was of particular interest for this study, since IGWs are favoured under this condition and hence enhance mixing (Chimonas, 2002; Cuxart et al., 2006). Indications of the existence of passage of wave events within the stable ABL are found in sodar records; Rao et al. (2004) observed several solitary-like wave events in the central area of Rome, Italy, with depths ranging up to $500 \mathrm{~m}$.

Since the loading of suspended particulates in the lower troposphere is directly linked with the visibility, formation of fog and pollution aspects, it is worthwhile to examine the periodic nature of their fluctuations. In this perspective, the vertical profile data of aerosols with good spatial and temporal resolutions would aid in exploring the oscillations inherent in a tropical atmosphere with stable stratification. In this paper, we examine the characteristic oscillations of tropospheric aerosol backscatter signal from a polarized lidar and that of surface weather parameters from an automated weather station.

\section{Experimental site and synoptic background}

The experiment was conducted at the Indian Institute of Tropical Meteorology (IITM) in Pune $\left[18^{\circ} 32^{\prime} \mathrm{N}, 73^{\circ} 51^{\prime} \mathrm{E}\right.$, $559 \mathrm{~m}$ above mean sea level (a.m.s.l.)], a semi-arid tropical urban site in the west-central India. The experimental site is surrounded to its three sides by hillocks of about $150 \mathrm{~m}$ above ground, embedded in a valley-like station and it is on the leeward side of the Western Ghats of India. The city experiences distinct seasons namely the winter (December, January and February), pre-monsoon (March, April and May), summer monsoon (June, July, August and September) and postmonsoon (October and November) seasons. The winds are easterly/northeasterly during winter and pre-monsoon, and westerly/southwesterly during the summer monsoon (Raj and Deshpande, 2008). The thermal structure of the atmosphere is drastically different during day and night hours, especially during winter. The winter nights are characterized by elevated inversion layers, which are produced due to strong radiational cooling at the ground level and associated relative heating at upper levels (Devara et al., 1998; Tiwari et al., 2003). Thus the atmosphere will be more stable during the winter months. The surface temperature in the experimental location ranges from 20 to $35^{\circ} \mathrm{C}$ during day-time and from 5 to $21^{\circ} \mathrm{C}$ during night-time in the winter times. The corresponding temperatures in the pre-monsoon are 23 $44^{\circ} \mathrm{C}$ and $22-28^{\circ} \mathrm{C}$, whereas in the monsoon time, it is 20 $28^{\circ} \mathrm{C}$ and $15-21^{\circ} \mathrm{C}$, respectively (source: unpublished data from Automated Weather Station at IITM, for a period of last four years). Anthropogenic intervention (like construction activities, industrial development, increased traffic etc.) on the environment has increased the pollution level of the city during recent years (Dani et al., 2010). Since Pune is located in a hilly/mountainous terrain, it is reasonable to believe that the adjoining hillocks and thermal processes favour initiation and/or propagation of atmospheric instabilities which have close link to the variabilities of atmospheric constituents and meteorological parameters.

\section{Experiment and data}

The experiment was conducted using an autonomous Dual Polarization Micro Pulse Lidar (Foretech Model-DPMPL $0.3^{\mathrm{C}}$ ) which acquires vertical profiles of aerosol backscatter signal at high spatial and temporal resolutions in real-time mode upto stratospheric altitudes. This monostatic uni-axial system is being operated at $532 \mathrm{~nm}$ wavelength with a diodepumped solid-state (DPSS) neodymium-yttrium-aluminumgarnet (Nd:YAG) as the laser source. The laser output is eyesafe achieved via a low-energy, high repetition rate Nd:YAG laser with an expanded beam. The system can be operated either in parallel polarization or in alternate parallel and perpendicular polarization mode of the transmitted laser radiation. The receiver part consists of a compact SchmidtCassegrain telescope, with a high-speed detection and data acquisition and processing system. The transmitter-receiver alignment is achieved by means of an "octopus", which is a custom-made, high performance, microcontroller-based remote terminal unit that essentially controls the $x$ - and $y$ - axes of a mirror to align the laser beam with the receiver. A complete description of the system capabilities, working principle, and data acquisition and analysis can be found in the work of Devara et al. (2008).

The data used in the present investigation are aerosol backscatter profiles for every one minute interval at $2.4 \mathrm{~m}$ vertical resolution from DPMPL, and the concurrent surface temperature and wind obtained from a collocated automated weather station (AWS). Observational period is the winter months (January and February) of 2008 and 2009. Nighttime experiment of DPMPL was conducted during 14 perfectly clear-sky nights, 11 of which spreading in 2008 and 
the rest 3 nights falling in 2009. These days were identified based on near-similar clear-sky and atmospheric conditions. The use of still more number of observational days is restricted either by the presence of low level clouds, presence of moonlight, different meteorological conditions or lack of supporting data. The time span of observation is early morning, i.e., from 03:30 to $06: 49 \mathrm{~h}$ in 2008 , and from 00:00 to $03: 19 \mathrm{~h}$ in 2009; thus the number of clear-sky profiles for each day is restricted to 200 corresponding to $200 \mathrm{~min}$ of operation. The local time (h) is $05: 30 \mathrm{~h}$ ahead of UTC.

\section{Methodology}

The signal received by the lidar at each altitude is described in terms of the range square corrected signal (RCS), which is defined as:

$\operatorname{RCS}=\left[P(\lambda, z)-P_{0}(\lambda, z)\right] \times z^{2}$

where $P(\lambda, z)$ and $P_{0}(\lambda, z)$ denote the power of the backscattered light and the background signal from an altitude of $z$, respectively. As a preliminary step, the background noise - as well as range square - corrected backscatter signal (RCS) at multi levels, and the contemporaneous surface temperature and wind speed were subjected to spectral analysis for finding the prominent periodicities. Before subjecting to the core analysis, the trend of the data was removed by a least square linear fit to the observed data. Eliminating the trend of the data set will make sure that any possible natural variability has been got rid of. The program used for the spectral analysis was obtained from the website - http://www.geology.um.maine.edu/user/ Dan_Dixon/Matlab\%20Scripts/spctrm.m, which is originally given in the site of the Department of Earth Sciences, University of Maine, Orono. A brief discussion of the theory and formulation of the analysis is given in the next section.

The present harmonic program helps in identifying variations of power within a time series. By decomposing a time series into frequency domain, it is possible to determine the dominant modes of variability. Assume that one has a time series, $x_{n}$, with equal time spacing $\delta t$ and $n=0,1, \ldots N-1$. Now the time series that contain non-stationary power at many different frequencies are transformed with proper sinusoidal functions. After obtaining the spectral power for each periodicity, significance test is made to each level to see whether the power is due to a real harmonic component or due to a spike in the data. In order to determine significance levels for the spectra, one first needs to choose an appropriate background spectrum (Torrence and Compo, 1998). It is then assumed that different realizations of the atmospheric process will be randomly distributed about this mean or expected background, and the actual spectrum can be compared against this random distribution. For many geophysical phenomena, an appropriate background spectrum is either white noise (with a flat Fourier spectrum) or red noise (increasing power with decreasing frequency). These spectra are used to establish a null hypothesis for the significance of a peak in the power spectrum (Torrence and Compo, 1998). It is assumed that the time series has a mean power spectrum by theoretical considerations, and if a peak in the spectral power is significantly above this background spectrum, then it can be assumed to be a true feature with a certain percent confidence. In the present program, the background red noise spectrum is estimated based on the fitting of a first order autoregressive (AR1) process, being characteristic for many climatic processes. Hasselmann (1976) demonstrated that a first-order autoregressive (AR1) process is sufficient to explain the rednoise signature. Accordingly, the AR1 model is often used as null hypothesis to assess whether or not the variability recorded in a time series is consistent with a stochastic origin of this type (Schulza and Mudelsee, 2002). A peak in the spectrum of a time series can be tested for its significance against this red-noise background spectrum from an AR1 process. In the current package, red noise critical values are estimated by 15 simulation runs of the AR1 process with same lag 1 autocorrelation as the input variable (Gilman et al., 1963).

\section{Results and discussion}

The height-time-intensity (HTI) plots of the aerosol backscatter signal strength for four selected days (out of the 14 days under consideration), viz., 17 January and 14 February in 2008, and 24 February and 25 February in 2009 are, respectively, shown plotted in Fig. 1a-d. The time evolution of aerosol backscatter with height for these four days is representative of that for all the 14 experimental days and therefore the plots for other days are not shown herein. The bottom part of each of Fig. 1, which corresponds to a high intensity of backscatter photons, depicts the time evolution of the lower part of nocturnal boundary layer. The white solid lines in Fig. 1a-d show the time evolution of the surface temperature for the corresponding days. The intensity of backscatter signal decreases with height in each of the days and there are fluctuations of aerosol backscatter intensity at different epochs of time. Thus the lidar signal strength for all of these days shows considerable oscillations with the progress of time. On an average, the surface temperature during the experimental period ranged between $20-13^{\circ} \mathrm{C}$. The decreasing trend is obvious for the surface temperature (marked as white solid lines in Fig. 1a-d) for all the days and it is monotonically decreasing. The interesting feature seen in the lidar backscatter variations is that it is, by and large, in accordance with the temperature fluctuations.

In order to examine the role of wind in the process of aerosol loading and distribution, the time evolution of corresponding wind speed at the surface during the entire experimental period for the above four days have been shown plotted in Fig. 2a-b, in addition to the relative humidity (RH) 

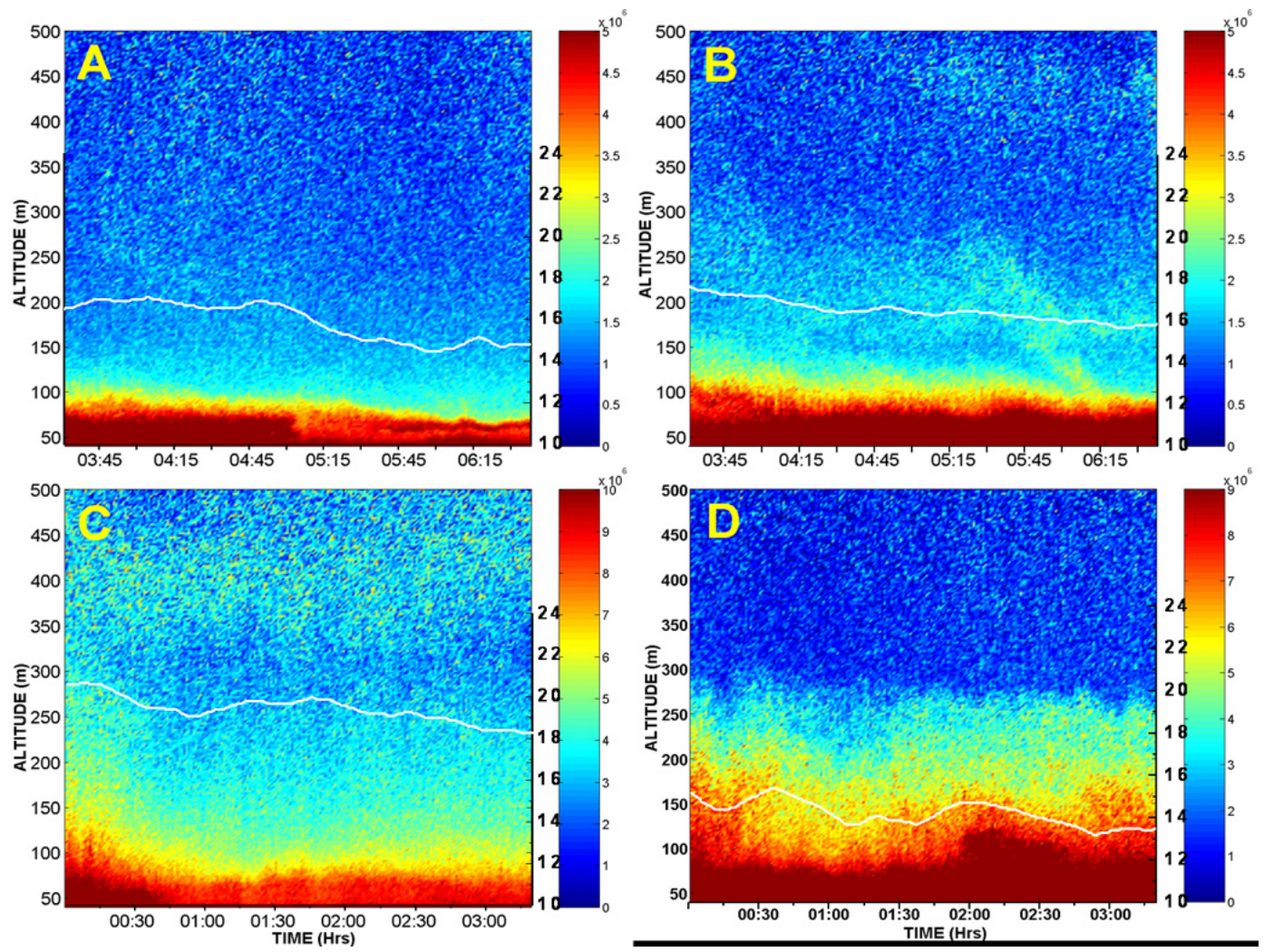

Fig. 1. Height-time-intensity plot of range-square corrected aerosol backscatter signal on (A) 17 January 2008; (B) 14 February 2008 ; (C) 24 February 2009, and (D) 25 February 2009. The white solid line imposed on all the plots is the time-evolution of corresponding day's surface temperature.

for the respective days (Fig. 2c-d). In general, it is noted that there is oscillatory/intermittent behaviour in the wind speed with low values towards the ending hours compared to the beginning of the experiment. Additionally, it should be noticed that the wind was calm and it never exceeded $2 \mathrm{~m} \mathrm{~s}^{-1}$ at any occasion on any of the days. Even though the RH showed a lot of fluctuations, the trend was slightly on the increasing side on most of the days and is just the opposite to that of temperature evolution.

In the present study, we have concentrated our analysis mainly within the nocturnal boundary layer, especially within the stable layer. For this purpose, we estimated the average stable boundary layer height with the help of potential temperature profile. Since there is a lack of in-situ temperature profile and other meteorological data, those parameters were obtained for the experimental location from the operational Year of Tropical Convection (YOTC) data available in the website of European Centre for Medium-Range Weather Forecasts (ECMWF). The resolution of this data set is T799 L25 (25 km horizontal grids and 25 vertical levels spanning from $1000 \mathrm{hPa}$ to $1 \mathrm{hPa}$ ). This high spatial-resolution operational data is available from the URL: http://data-portal.ecmwf.int/data/d/yotc_od/class= od/levtype $=\mathrm{pl} / \mathrm{type}=\mathrm{an} /$. The top of the stable boundary layer
(SBL) has been identified where the vertical potential temperature gradient noticeably decreases (Ford et al., 2008). Unlike the daytime mixed layer which has a well defined top, the SBL has a poorly-defined top that smoothly blends into the residual layer above (Devara et al., 2009). Moreover, at the SBL top, the mean virtual potential temperature tends to be nearly constant and the turbulence intensity is a small fraction of its surface value (Stull, 1988). The profile of mean potential temperature and virtual potential temperature has been given in Fig. 3. From these profiles, the average stable layer height is estimated to be about $560 \mathrm{~m}$. The identified SBL top could be verified again from the lidar backscatter data (figure not shown). Accordingly, the stable layer height was estimated from the normalized concentration gradients of aerosol backscatter profiles by the method discussed in the work of Sasano et al. (1982). The SBL heights identified by both the methods agree reasonably well within the expected level of uncertainty in both the methods. Figure 4 portrays typical height-wise variations in instantaneous fluctuations of range-corrected lidar backscatter at discrete altitudes on 14 February 2008 (Fig. 4a) and 24 February 2009 (Fig. 4b) which were subjected to spectral analysis. Moreover, the trend in the fluctuations of lidar signal at each altitude is marked by blue dotted lines. As described earlier, the 

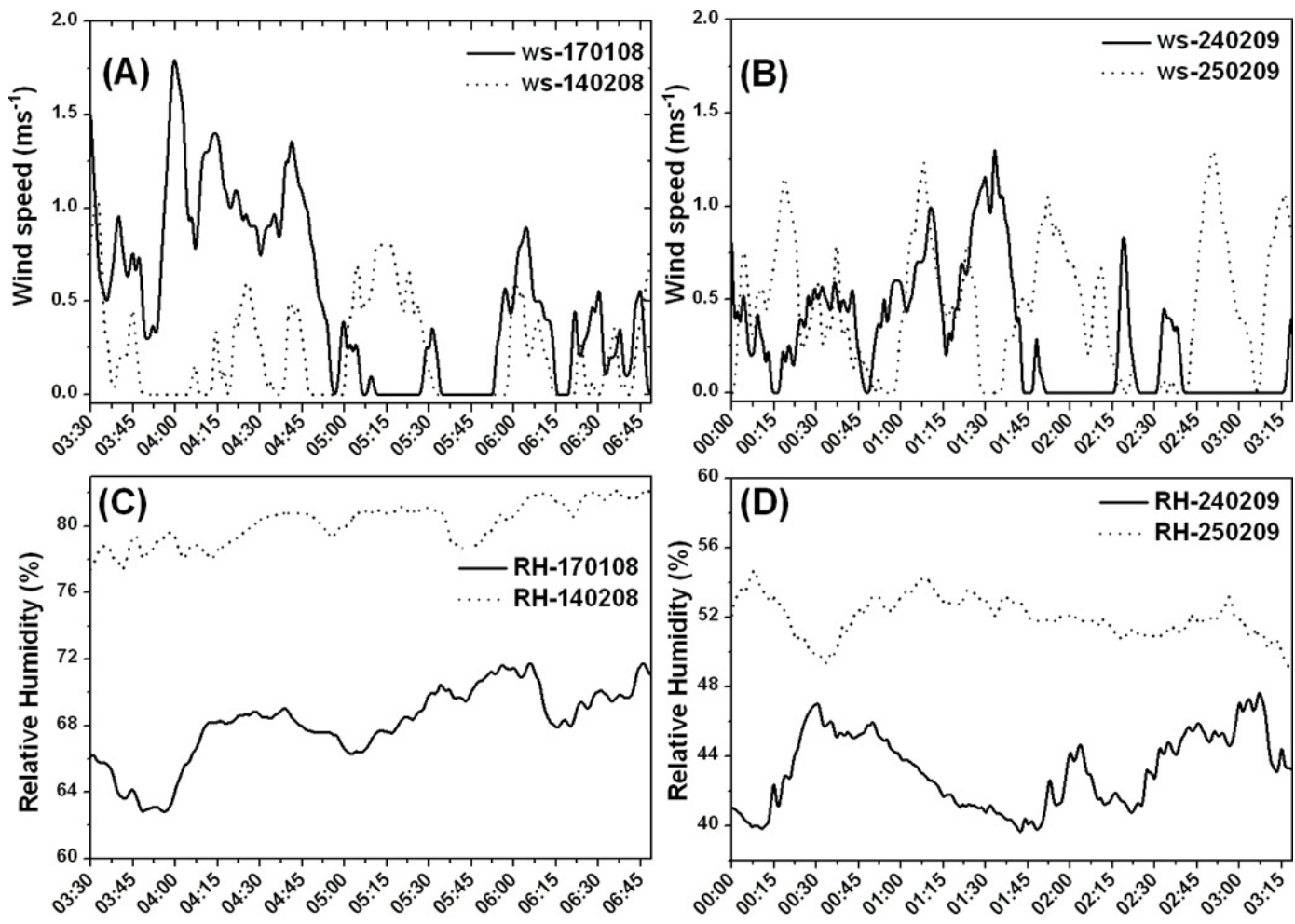

\section{Time (Hrs)}

Fig. 2. The time variation of surface wind speed in $\mathrm{ms}^{-1}$ on: (A) 17 January and 14 February 2008; (B) 24 February and 25 February 2009. (C) and (D) are, respectively, for (A) and (B) but for surface relative humidity (\%).
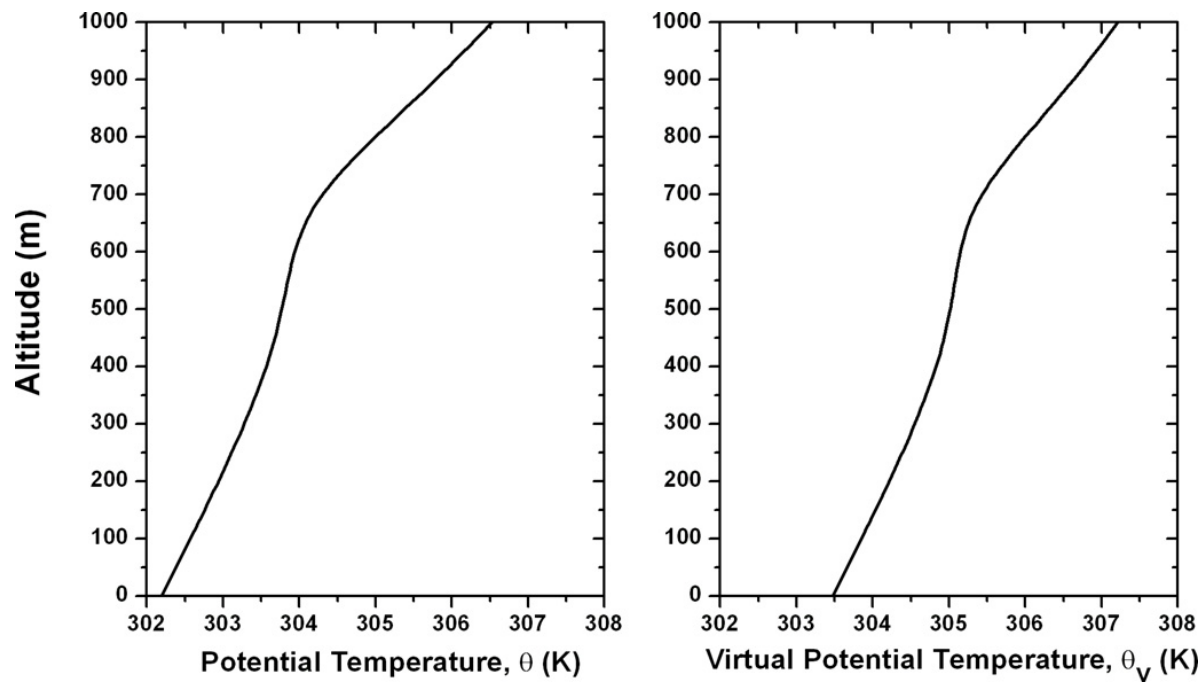

Fig. 3. Vertical profile composite of mean potential temperature $(\mathrm{K})$ and virtual potential temperature $(\mathrm{K})$ for all the experimental days in 2008 and 2009.

decrease in strength of backscatter with height is noticeable in these figures also. Due to the prevailing stable condition, in general, there exists much less turbulence or convective thermals in the lower stable layers in the winter nights. Sub- sequently the atmospheric burden of aerosols in higher height levels could be drastically reduced and the resultant concentration at lower altitudes can enhance due to gravitational settling. This aspect is robustly evident from Fig. 4. 


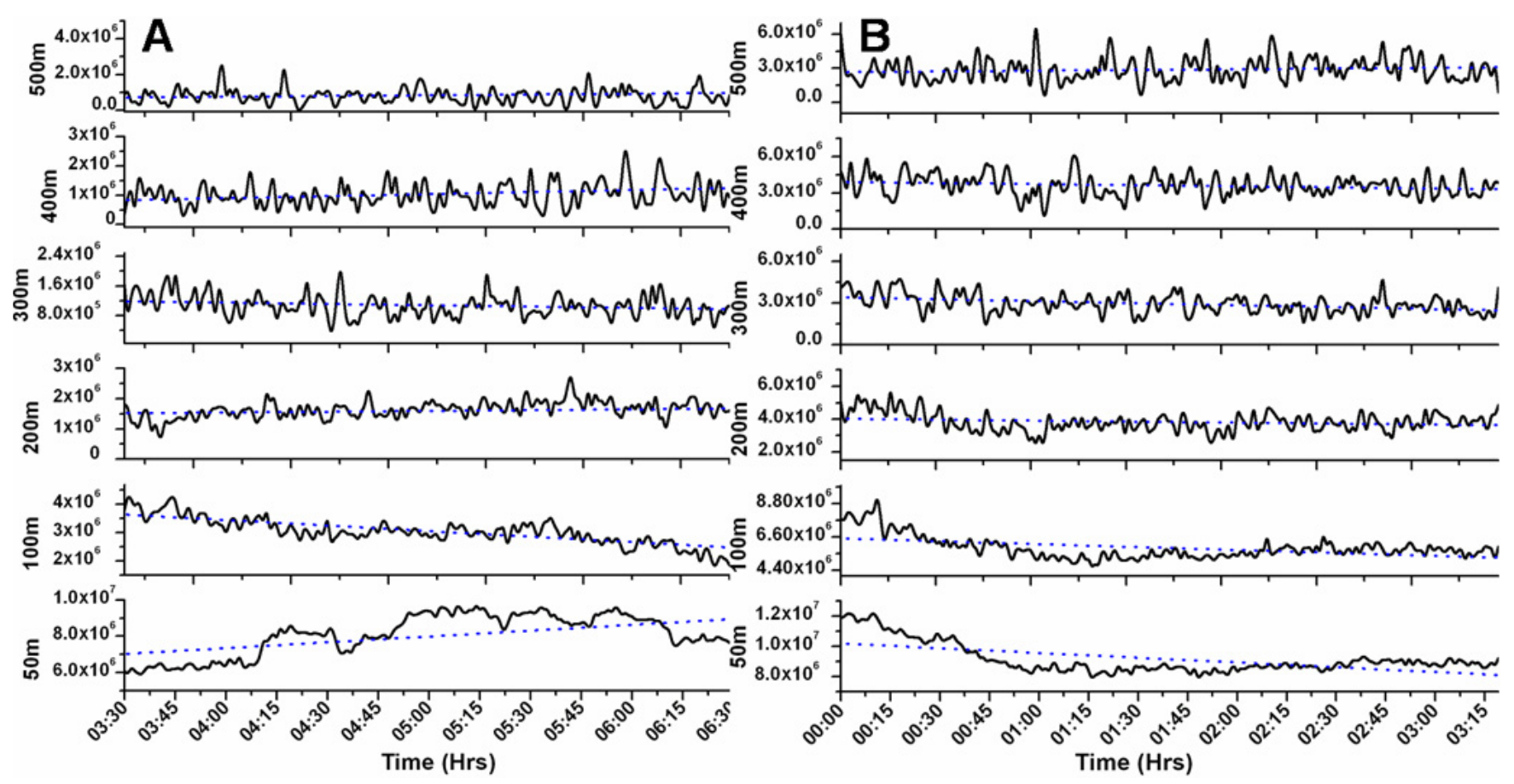

Fig. 4. Time-dependent evolution in fluctuations of lidar backscatter at discrete altitudes on (A) 14 February 2008 and (B) 24 February 2009. The blue dotted lines at all altitudes show the trend in backscatter fluctuations.

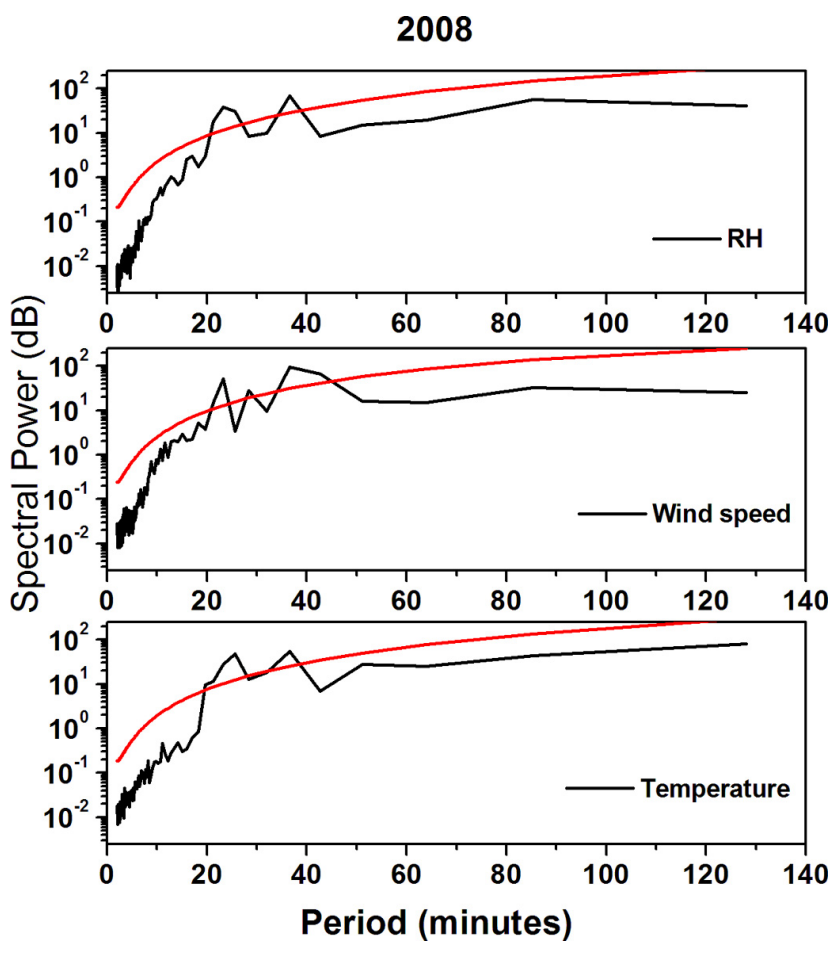

Fig. 5. Composite spectral power for the surface temperature (bottom), surface wind speed (middle) and relative humidity (top) for all the experimental days in 2008 .
Figure 5 shows the spectral power for the surface level temperature, wind and RH on all days in 2008. This has been achieved by obtaining the spectral power for each meteorological parameter for different days of the particular year and averaging the spectral powers to get a composite picture for the same parameter for the specified year. The red dotted line in each panel represents the $95 \%$ statistical level of confidence. If the spectral power of any periodicity is above this level, it is statistically significant at $5 \%$ level. From this figure, it is clear that periodicities ranging from 20 to $40 \mathrm{~min}$ have high spectral power above the level of confidence. At this point, it is worthwhile to note that a five-point moving average has been performed in order to eliminate any spike in the original data set and thereby smooth it out before subjecting to spectral analysis. The composite power spectrum for aerosol backscatter at discrete height levels of 50, 100, $200,300,400$ and $500 \mathrm{~m}$ for the year (2008) is shown plotted in Fig. 6 in the clockwise direction from the bottom left. The different altitude levels under consideration lie within the height of nocturnal stable boundary layer. A characteristic feature of the statically stable layer is that it tends to suppress turbulence, while the developing nocturnal jet enhances wind shears that tend to generate turbulence. As a result, turbulence sometimes occurs in relatively short bursts that can cause mixing in the SBL (Stull, 1988). As a result, there could be fluctuations in the lidar signal as has been shown in Fig. 1. This feature is again supported by earlier studies (Mahrt et al., 1998) which affirm that within the nocturnal 
2008
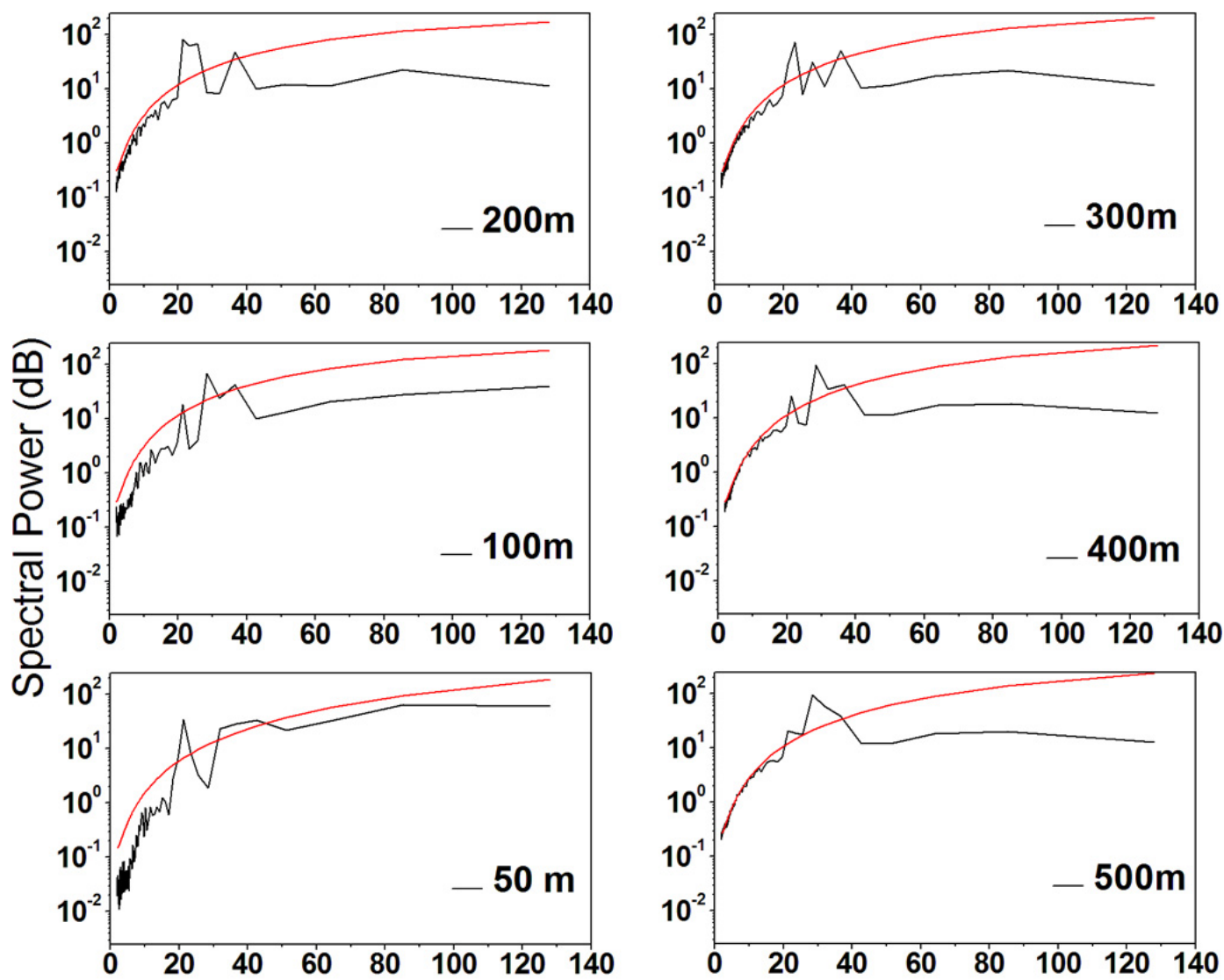

Period (minutes)

Fig. 6. Composite spectral power for aerosol backscatter signal at $50 \mathrm{~m}, 100 \mathrm{~m}, 200 \mathrm{~m}, 300 \mathrm{~m}, 400 \mathrm{~m}$ and $500 \mathrm{~m}$, for all the experimental days in 2008 .

boundary layer, turbulence is observed to be intermittent with episodes of vigorous mixing delineated by quiescent periods; the vigorous episodes contain waves and related dynamic features (Hogstrom, 1990) and overturning breaking waves (Hodges, 1967). Consequently, the presence of periodic fluctuations can be expected even in the SBL. What peculiarity seems to be interesting in Fig. 6 is the highest spectral power centered around the periodicities $20-40 \mathrm{~min}$ in all the above altitudes. It should be noted that the power of this dominant mode is slightly varying with height. There are very short-scale periodicities observed but they are not significant. From the above explanations based on Figs. 5 and 6, it implies that the processes responsible for the variations in meteorological parameters may also be responsible for the kind of oscillations of atmospheric components such as aerosols. This observation leads to reinforcing the postulation that the role of surface temperature and wind speed on the time evolution of boundary layer is to be taken well into account while examining the various processes in the boundary layer. This is reasonably supported by the fact that the dominant period- icity of around $20-40$ min observed in the temperature- and wind-oscillations (see Fig. 5) is also observed in the power spectra of aerosol backscatter signal strength at all vertical levels.

In a similar manner as discussed in the previous section, the composite spectral power for the surface temperature, wind and RH for all the days in 2009 is given in Fig. 7. Here also, in surface meteorological parameters, periodicity centered around $20-40 \mathrm{~min}$ is the prominent one. Regarding the oscillations of lidar return signals in 2009, the power spectra (Fig. 8) show a common periodicity of $20-40 \mathrm{~min}$ for each discrete height level. There is no significant shortscale periodicities observed in these events. Combined with the previous example of 2008, it can be argued that surface meteorological parameters, especially temperature and wind speed, have crucial role in modulating the nocturnal boundary layer (especially SBL) inducing quasi-periodic fluctuations of different atmospheric constituents. The periodicity observed in the meteorological parameters also may have influence on the vertical distribution of aerosols. During winter 


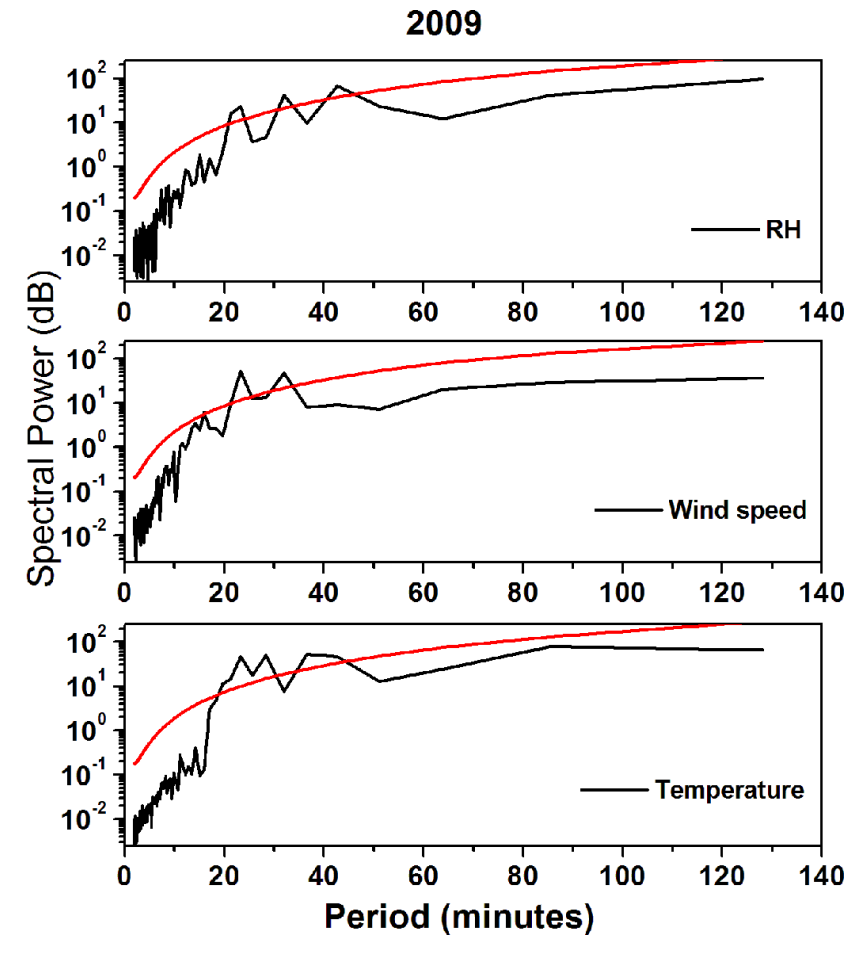

Fig. 7. Same as Fig. 5 but for all the experimental days in 2009.

nights, due to stably stratified nature of the atmosphere and also due to temperature inversions, there is a high probability of aerosol layer formation at lower levels. This aerosol layer can interact with atmospheric humidity content and can grow under favourable conditions. This would lead to haze layer formation and may affect the visibility at lower altitudes (Tiwari et al., 2003). Hence, a common periodicity in wind and temperature could alter the spatio-temporal distribution of suspended particulates.

It is worthwhile to notice that, in both of the examples given above, the periodicity of around $20-40 \mathrm{~min}$ is frequent to the meteorological parameters as well as aerosol vertical distributions. This leads to the postulation that one common trigger is accountable for the quasi-periodic oscillations of all the concerned parameters during the entire span of the experiment. Also, the same periodicity at discrete vertical level suggests that the wave could be propagating upward and exchanging energy between the lower and higher height levels thus producing the subsequent responses at different altitudes. This type of vertical propagation and amplification/damping of waves have been reported in earlier studies (for e.g., Kniffka et al., 2009). Stull (1988) gives a theoretical background for the presence of gravity waves in the stable boundary layer. Sachdev and Satya Narayanan (1982) have pointed out that small wave perturbations amplify and may eventually break when the wind shear becomes large enough to overcome the stabilizing influence of the density stratification.
Another interesting feature to be noted is the commonality in the dominant periodicity, eventhough the data under analysis is spread into two different timings for the two years. It is, therefore, reasonable to believe that this type of oscillation is inherent almost during the entire nocturnal regime in the winter atmosphere over this experimental site. In the literature, several papers demonstrate that gravity waves of periodicities ranging from shorter to longer scales can coexist in the atmosphere. Subba Reddy et al. (2005) have reported the gravity wave activity by analyzing the wind components in the troposphere and lower stratosphere using the MST radar at another tropical station Gadanki (station with almost similar type of topography), and found gravity wave of periodicities of $54,42,38,32,30,26,25,21,13 \mathrm{~min}$ etc. during the winter months. By employing the same MST Radar, Dhaka et al. (2001) have also reported gravity waves of 10-50 min periodicity, but for summer months of 1995 and 1996. Since a stratified fluid has the ability to support and propagate wave motion; and since the atmosphere is stably stratified on most of the occasions, it favours the existence of gravity waves (Nappo, 2002). Quasi-periodic oscillations of 10-20 min were observed in net flux of long-wave radiation, surface temperature and wind during a typical winter day by a study conducted by Roach (1976) and an explanation for the same has been given based on the effect of atmospheric gravity wave activity. Quasi-periodic oscillations with a period of about $40 \mathrm{~min}$ are observed in visibility, temperature, water vapour, wind speed and long wave radiation at a station Cabauw $\left(51^{\circ} 58^{\prime} \mathrm{N}, 4^{\circ} 56^{\prime} \mathrm{E}\right)$ having a variety of topographical features and situated south-west of De Bilt, in the Netherlands (Duynkerke, 1991). An interpretation of the oscillations is given in terms of gravity waves, which are rather typical under very stable conditions. In model simulations, Welch et al. (1986) found fluctuations in liquid water content, temperature, radiative fluxes and wind speed; and the time scale of the fluctuations varied from $30 \mathrm{~min}$ to $120 \mathrm{~min}$. High resolution measurements from radars, lidars, numeric modelling and theoretical studies have reported that short-period gravity waves (of periodicity $<1 \mathrm{~h}$ ) exist in the atmosphere due to various generation mechanisms (Ratnam et al., 2008, and references therein). In all these studies, it is emphasized that orography is pointed out to be one of the responsible factors for the generation of internal gravity waves (Debashis et al., 2009). Hence, in the present study, the periodic undulations of the meteorological parameters and aerosol return signals can be ascribed to the possible modulation by atmospheric gravity waves of the same observed periodicity. This has a direct bearing on the comprehensive understanding of the variabilities of atmospheric constituents and subsequent prediction perspectives of a variety of weather processes. 
2009
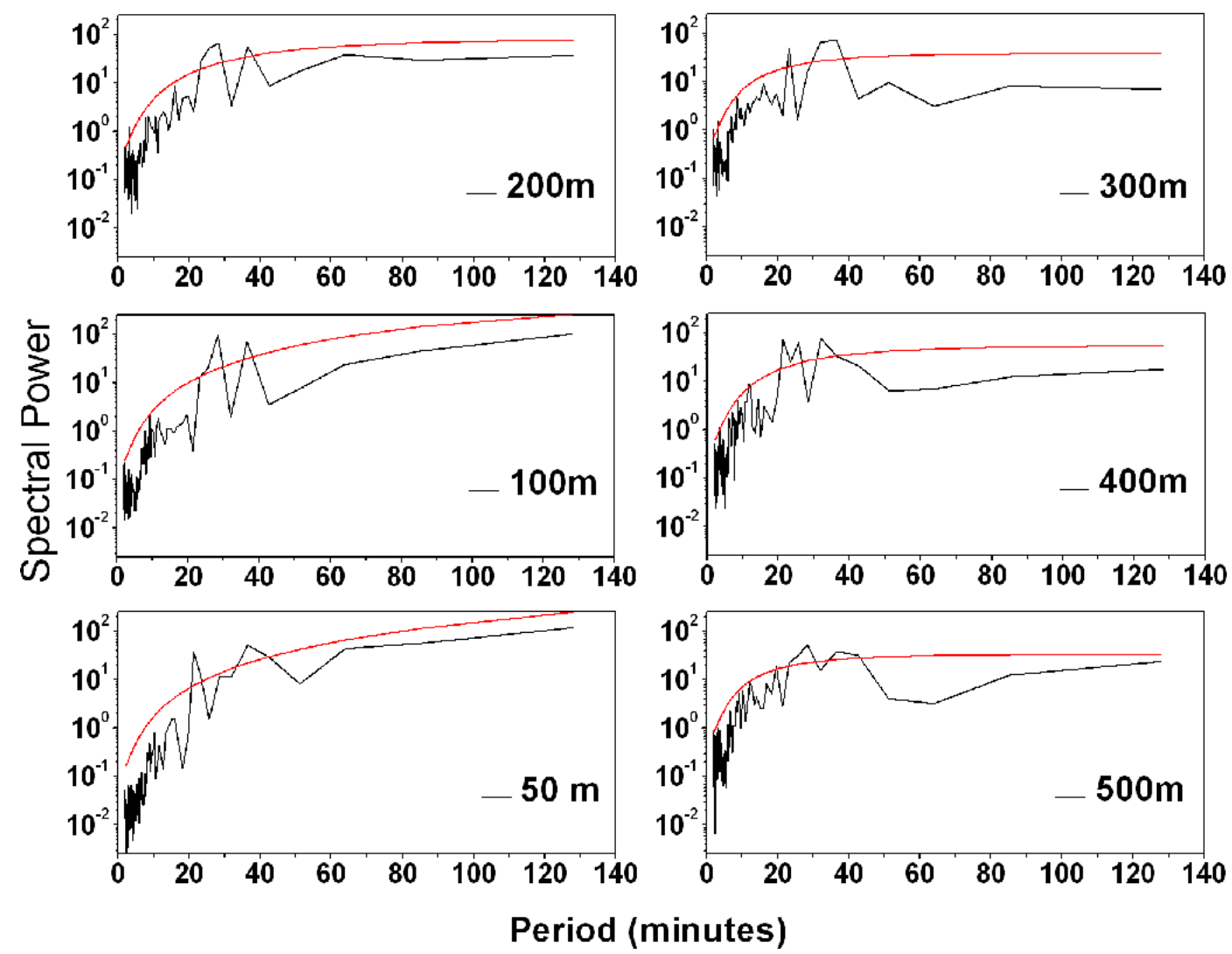

Fig. 8. Same as Fig. 6 but for all the experimental days in 2009.

\section{Conclusions}

Overnight experimental data of aerosol backscatter signal strength from an autonomous micro pulse lidar and concurrent surface meteorological parameters were subjected to spectral analysis to explore the dominant mode of variability inherent in them, on 14 clear-sky nights in the backdrop of a stable atmosphere. The urban boundary layer under current investigation possesses certain characteristic frequencies. The common periodicity observed is $20-40 \mathrm{~min}$ in the meteorological fields. The same frequency domains caused by wave-like structures are subsequently seen in the quasiperiodic oscillations of aerosol distributions in the vertical. It is further clear that surface temperature and wind could play a crucial role in the aerosol distribution within the nocturnal boundary layer. The modulation of the variations in meteorological parameters and in turn in the wavy nature of aerosol signals is ascribed to be due to the presence of vertically propagating atmospheric gravity waves which is evident from the present investigation. This type of waves can carry the momentum and energy vertically thereby exchanging them at different altitudes. It is, however, worth mentioning that the present analysis is based on a limited number of samples and hence might slightly affect the results, particularly the reliability and accuracy of the wave periodicities observed in the investigation. As the lidar and other concurrent ancillary observations are being continued/augmented at this location, more data sets for longer period will be examined in the near future to substantiate the same. The present results have substantial implications in the diagnostic understanding and further attempts in the prediction perspectives of versatile atmospheric phenomena like fluctuations in tropical weather.

Acknowledgements. The program for spectral analysis was obtained from the website of the Department of Earth Sciences, University of Maine, Orono (URL: http://www.geology.um.maine.edu/ user/Dan_Dixon/Matlab\%20Scripts/spctrm.m), and the authors acknowledge them sincerely. We thank the authorities of ECMWF YOTC Project for supplying the data for some of our analysis. The authors are highly grateful to the "Aerosol and Cloud Physics Laboratory for Weather and Climate Studies". Thanks are also due to Director, IITM for encouragement and infrastructural facilities. One of the authors (MGM) sincerely acknowledges the research fellowship from the Council of Scientific and Industrial Research (CSIR), Government of India. We thank two anonymous reviewers whose comments on an earlier version of the paper led to substantial improvement of the paper. 
Topical Editor P. M. Ruti thanks two anonymous referees for their help in evaluating this paper.

\section{References}

Chimonas, G.: On internal gravity waves associated with the stable boundary layer, Bound.-Lay. Meteorol., 102, 139-155, 2002.

Cuxart, J., Holtslag, A. A. M., Beare, R. J., Bazile, E., Beljaars, A., Cheng, A., Conangla, L., Ek, M., Freedman, F., Hamdi, R., Kerstein, A., Kitagawa, H., Lenderink, G., Lewellen, D., Mailhot, J., Mauritsen, T., Perov, V., Schayes, G., Steeneveld, G.-J., Svensson, G., Taylor, P., Weng, W., Wunsch, S., and Xu, K.-M.: Single-column model inter-comparison for a stably stratified atmospheric boundary layer, Bound-Lay. Meteorol., 118, 273-303, 2006.

Dani, K. K., Raj, P. E., Devara, P. C. S., Pandithurai, G., Sonbawne, S. M., Maheskumar, R. S., Saha, S. K., and Rao, Y. J.: Long-term trends and variability in measured multi-spectral aerosol optical depth over a tropical urban station in India, Int. J. Climatol., published online, doi:10.1002/joc.2250, 2010.

Debashis, N., Ratnam, M. V., Rao, V. V. M. J., Murthy, B. V. K., and Rao, S. V. B.: Gravity wave characteristics observed over a tropical station using high-resolution GPS radiosonde soundings, J. Geophys. Res., 114, D06117, doi:10.1029/2008JD011056, 2009.

Devara, P. C. S., Raj, P. E., Sharma, S., and Pandithurai, G.: Lidarobserved long-term variations in urban aerosol characteristics and their connection with meteorological parameters, Int. J. Climatol., 14, 581-591, 1994.

Devara, P. C. S., Pandithurai, G., Raj, P. E., Maheskumar, R. S., and Dani, K. K.: Atmospheric aerosol-cloud-stability relationship as observed with optical and radio remote sensing techniques, Atmos. Res., 49, 65-76, 1998.

Devara, P. C. S., Raj, P. E., Dani, K. K., Pandithurai, G., Kalapureddy, M. C. R., Sonbawne, S. M., Rao, Y. J., and Saha, S. K.: Mobile lidar profiling of tropical aerosols and clouds, J. Atmos. Ocean. Tech., 25, 1288-1295, 2008.

Devara, P. C. S., Manoj, M. G., and Jaya Rao, Y.: Role of aerosols in monsoon clouds and precipitation: An observational perspective, Mausam, Diamond Jubilee Volume, 155-162, 2009.

Dhaka, S. K., Devrajan, P. K., Shibagaki, Y., Choudhary, R. K., and Fukao, S.: Indian MST radar observations of gravity wave activities associated with tropical convection, J. Atmos. SolarTerr. Phys., 63, 1631-1642, 2001.

Duynkerke, P. G.: Observation of a quasi-periodic oscillation due to gravity waves in a shallow radiation fog, Q. J. Roy. Meteorol. Soc., 117, 1207-1224, 1991.

Ford, B. J., Morris, G. A., Thompson, E., Rappenglueck, B., Lefer, B., Byun, D. W., Li, X., Perna, R., Boudreaux, R., Day, B. M., Pedemonte, L., and Chow, A.: The impact of residual layer ozone on surface ozone levels in Houston, Texas during TexAQS II, 10th Conference on Atmospheric Chemistry, P1.11, The 88th Annual Meeting of the American Meteorological Society, New Orleans, LA, 20-24 January 2008.

Fritts, D. C. and Alexander, M. J.: Gravity wave dynamics and effects in the middle atmosphere, Rev. Geophys., 41(1), 1003, doi:10.1029/2001RG000106, 2003.

Geller, M. A., Liu, H., Richter, J. H., Wu, D., and Zhang, F.: Gravity waves in weather, climate and atmospheric chemistry: Issues and challenges for the community, Technical Report, The Institute for
Integrative and Multidisciplinary Earth Studies (TIIMES) at the National Center for Atmospheric Research (NCAR), 2006.

Gill, A. E.: Atmosphere-Ocean Dynamics, Academic Press Inc., London, 662 pp., 1982.

Gilman, D. L., Fuglister, F. J., and Mitchel Jr., J. M.: On the power spectrum of red noise, J. Atmos. Sci., 20(2), 182-184, 1963.

Hasselmann, K.: Stochastic climate models: Part I. Theory, Tellus, 28(6), 473-485, 1976.

Hodges Jr., R. R.: Generation of turbulence in the upper atmosphere by internal gravity waves, J. Geophys. Res., 72, 34553458, 1967.

Hogstrom, U.: Analysis of turbulence structure in the surface layer with a modified similarity formulation for near neutral conditions, J. Atmos. Sci., 47, 1949-1972, 1990.

Intergovernmental Panel on Climate Change, IPCC: Climate Change: The Scientific Basis, Chapter 5, (Aerosols, their direct and indirect effects), edited by: Penner, J. E., Andreae, M., Annegarn, H., Barrie, L., Feichter, J., Hegg, D., Jayaraman, A., Leaitch, R., Murphy, D., Nganga, J., and Pitari, G., 2001.

Jayaraman, A., Lubin, D., Ramachandran, S., Ramanathan, V., Woodbridge, E., Collins, W. D., and Zalpuri, K. S.: Direct observations of aerosol radiative forcing over the tropical Indian Ocean during the January-February 1996 pre-INDOEX cruise, J. Geophys. Res., 103(D12), 13827-13836, 1998.

Kniffka, A., Ziemann, A., Chunchuzov, I., Kulichkov, S., and Perepelkin, V.: Anisotropy in internal gravity waves in conditions of a stable nocturnal boundary layer, Meteorol. Z., 18, 331-337, 2009.

Mahrt, L., Sun, J., Blumen, W., Delani, T., and Oncley, S.: Nocturnal boundary-layer regimes, Bound-Lay. Meteorol., 88, 255278, 1998.

Mapes, B. E.: Gregarious tropical convection, J. Atmos. Sci., 50, 2026-2037, 1993.

Menon, S., Hansen, J., Nazarenko, L., and Luo, Y.: Climate effects of black carbon aerosols in China and India, Science, 297, 22502253, 2002.

Nappo, C. J.: An Introduction to Atmospheric Gravity Waves, Academic Press, USA, pp. 276, 2002.

Nilsson, E. D.: Planetary boundary layer structure and air mass transport during the International Arctic Ocean Expedition 1991, Tellus B, 48, 178-196, 1996.

Nilsson, E. D. and Bigg, E. K.: Influences on formation and dissipation of high arctic fogs during summer and autumn and their interaction with aerosol, Tellus B, 48, 234-253, 1996.

Niranjan, K., Madhavan, B. L., and Sreekanth, V.: Micro pulse lidar observation of high altitude aerosol layers at Visakhapatnam located on the east coast of India, Geophys. Res. Lett., 34, L03815, doi:10.1029/2006GL028199, 2007.

Pandithurai, G., Dipu, S., Dani, K. K., Tiwari, S., Bisht, D. S., Devara, P. C. S., and Pinker, R. T.: Aerosol radiative forcing during dust events over New Delhi, India, J. Geophys. Res., 113, D13209, doi:10.1029/2008JD009804, 2008.

Raj, P. E. and Deshpande, S. M.: Pre-monsoon to monsoon change in direction of vertical motions in the tropical lower troposphere from UHF radar observations, Geophys. Res. Lett., 35, L15808, doi:10.1029/2008GL034421, 2008.

Rao, M. P., Castracane, P., Casadio, S., Fua, D., and Fiocco, G.: Observations of atmospheric solitary waves in the urban boundary layer, Bound-Lay. Meteorol., 111, 85-108, 2004. 
Ratnam, M. V., Babu, A. N., Rao, V. V. M. J., Rao, S. V. B., and Rao, D. N.: MST radar and radiosonde observations of inertia-gravity wave climatology over tropical stations: Source mechanisms, J. Geophys. Res., 113, D07109, doi:10.1029/2007JD008986, 2008.

Roach, W. T.: On some quasi-periodic oscillations observed during a field investigation of radiation fog, Q. J. Roy. Meteorol. Soc., 102, 355-359, 1976.

Ross, A. N. and Vosper, S. B.: Numerical simulations of stably stratified flow through a mountain pass, Q. J. Roy. Meteorol. Soc., 129, 97-115, 2003.

Sachdev, P. L. and Satya Narayanan, A.: Instabilities of internal gravity waves in stratified shear flows, Indian J. Pure. Ap. Mat., 13(9), 989-996, 1982.

Sasano, Y., Shigematsu, A., Shimizu, H., Takeuchi, N., and Okuda, M.: On the relationship between the aerosol layer height and mixed layer height determined by laser radar and low-level radiosonde observations, J. Meteorol. Soc. Jpn, 60, 889-895, 1982.

Schulza, M. and Mudelsee, M.: REDFIT: estimating red-noise spectra directly from unevenly spaced paleoclimatic time series, Comput. Geosci., 28, 421-426, 2002.

Stull, R. B.: An Introduction to Boundary Layer Meteorology. Kluwer Academic Publications: Dordrecht, 666 pp., 1988.

Subba Reddy, I. V., Narayana Rao, D., Narendra Babu, A., Venkat Ratnam, M., Kishore, P., and Vijaya Bhaskara Rao, S.: Studies on atmospheric gravity wave activity in the troposphere and lower stratosphere over a tropical station at Gadanki, Ann. Geophys., 23, 3237-3260, doi:10.5194/angeo-23-3237-2005, 2005.
Tiwari, Y. K., Devara, P. C. S., Raj, P. E., Maheskumar, R. S., Pandithurai, G., and Dani, K. K.: Tropical urban aerosol distributions during pre-sunrise and post-sunset as observed with lidar and solar radiometer at Pune, India, J. Aerosol Sci., 34, 449-458, 2003.

Torrence, C. and Compo, G. P.: A practical guide to wavelet analysis, B. Am. Meteorol. Soc., 79, 61-78, 1998.

Tripathi, S. N., Dey, S., Tare, V., and Satheesh S. K.: Aerosol black carbon radiative forcing at an industrial city in northern India, Geophys. Res. Lett., 32, L08802, doi:10.1029/2005GL022515, 2005.

Vinoj, V., Babu, S. S., Satheesh, S. K., Moorthy, K. K., and Kaufman, Y. J.: Radiative forcing by aerosols over the Bay of Bengal region derived from ship-borne, island-based, and satellite (Moderate-Resolution Imaging Spectroradiometer) observations, J. Geophys. Res., 109, D05203, doi:10.1029/2003JD004329, 2004.

Welch, R. M., Ravichandran, M. G., and Cox, S. K.: Prediction of quasi-periodic oscillations in radiation fogs. Part I: comparison of simple similarity approaches, J. Atmos. Sci., 43, 633-651, 1986. 